\title{
OBSERVAÇÕES SOBRE O SIGNIFICADO JURÍDICO DA RESPONSABILIDADE POLÍTICA*
}

Eric Millard**

1 Posição do problema. 2 A dificuldade do problema. 3 Delimitação do problema. 4 Usos do conceito. $5 \mathrm{~A}$ impossível significação no discurso normativo. 5.1 Utilização diversificada do termo. 5.2 Variabilidade do conceito. 5.3 Substitutividade do termo. 5.4 A utilização dúbia da expressão na Constituição Francesa. 5.5 Outros problemas sobre o significado da expressão. 6 Condições da construção de um conceito doutrinário. $7 \mathrm{O}$ modo de pensar prescritivo. 7.1 Ineficácia atual da expressão. 7.2 Pressupostos e consequências. $8 \mathrm{~A}$ perspectiva da expressão sob o ponto de vista descritivo. 8.1 A recusa da idéia de responsabilidade jurídica. 8.2 A admissão do conceito: a responsabilidade política é uma categoria de responsabilidade jurídica. 9É possível uma definição científica completa? 10 É ela um conceito sui generis? 11 Como construir este conceito? 11.1 A problemática sancionatória. 11.2 Ausência de ilícito jurídico propriamente dito. 11.3 A reintrodução, no âmbito jurídico, do ato ilícito e da sanção política. 12 Síntese conclusiva.

\section{RESUMO}

Este artigo trata das dificuldades que envolvem o significado da expressão responsabilidade política.

PALAVRAS-CHAVE

Análise crítica. Significado. Responsabilidade Política.

\section{POSIÇÃO DO PROBLEMA}

Este texto tem por único objetivo, independentemente de qualquer tentativa de construção teórica original, refletir sobre as significações que são trazidas pelo termo "responsabilidade política", nos diferentes discursos a que se referem, e tentar mostrar quais são as condições, as conseqüências e os pressupostos do uso de tal expressão.

A responsabilidade política parece ter adquirido o caráter de uma evidência aos olhos de uma grande parte da doutrina jurídica - caráter este que não invalida a leitura da maioria da literatura dos cientistas políticos. Pode-se, para ilustrar, referir-se, com Christian Bidegaray e Claude Emery ${ }^{1}$,

\footnotetext{
"Réplica de artigo publicado In: SÉGUR, Phillippe. Gouvernants, quelles responsabilité?. L'Harmattan, 2000 , sob o título «Observations sur la signification juridique de la responsabilité politique».

Professeur de droit public, Responsable du Master Droit Public à l'Université Paris-Sud 11 - Sceaux, autor de diversos livros e artigos jurídicos.
} 
às duas afirmações ordinariamente admitidas nos estudos sobre a organização jurídica dos regimes políticos:

a - Toda ação política supõe e demanda uma forma de responsabilidade;

b - A forma moderna da ação política é a forma jurídica.

Destes dois enunciados, pode-se tirar, então (pelo menos implicitamente), uma conclusão aparentemente lógica:

c - Nos regimes políticos modernos, existe uma responsabilidade política dos governantes (as variações possíveis sendo « nos regimes políticos modernos, deve existir uma responsabilidade política», ou "um regime no qual não exista responsabilidade política não é um regime político moderno, pois não é um regime juridicamente organizado - um Estado de Direito").

Refletir sobre o valor lógico real desta dedução, e notadamente, saber se os enunciados "a" e "b", respectivamente, são exatos, e se, a partir desta suposta exatidão é logicamente possível inferir aproximando-os de uma das conclusões propostas, ultrapassa, amplamente, o propósito desta análise.

Pode-se dizer, simplesmente que, na verdade, a conclusão se apresenta mais freqüentemente como uma afirmação de bom senso que como um resultado verificável de uma argumentação teórica. De qualquer maneira, parece impossível apreciar a afirmação ou a conclusão se não dispusermos de uma significação à qual se possa remeter, nestes enunciados, a responsabilidade política. Deste ponto de vista, duvida-se que o termo seja suscetível de ser provido de uma só significação (é o que pretendemos demonstrar), mesmo se ele se reveste de um aspecto familiar para aquele que o usa ou que a ele se refere.

Efetivamente, não é um estudante que concluiu apenas um semestre de Direito Constitucional do primeiro ano de Direito que pode saber o que é a responsabilidade política. $\mathrm{O}$ conceito the parece evidente, como, reconheçamos, nos parece a nós que a ele o ensinamos. Ora, este sentimento intuitivo de evidência do conceito de responsabilidade política é, evidentemente, um sentimento enganador, do qual, tanto ele como nós devemos desconfiar e que é muito freqüentemente a fonte de equívocos no conhecimento do Direito.

\section{A DIFICULDADE DO PROBLEMA}

Eis onde reside a primeira e principal dificuldade que o conceito de responsabilidade política causa à Ciência Jurídica.

Toda ciência, toda filosofia é, inicialmente, uma crítica da língua. A língua de uma ciência não é a língua natural. Um conceito deve ter uma significação para que possamos estabelecer, com ele, um raciocínio verificável. O conhecimento do Direito, enquanto atividade científica, pressupõe então este trabalho crítico sobre os conceitos que ele utiliza. 
Ora, a responsabilidade política da qual nós falamos aqui é, evidentemente, em primeiro lugar, um termo vago da língua natural comum (de lá vem o que nos parece familiar), suscetível, portanto, de remeter a múltiplas utilizações (utilização no contexto jornalístico, utilização no contexto político, etc.) e ainda ter várias significações: ele significará, em função do locutor e do local da locução, a responsabilidade parlamentar dos governantes; a responsabilidade penal dos ministros; ou outras coisas, ainda menos precisas, como um dever por parte dos que fazem a política de dever prestar contas, sem que os procedimentos, os motivos, as sanções ou os destinatários sejam mais precisamente identificados ou supostos.

Termo suscetível de ter, na língua natural, vários significados, a responsabilidade política é, por esta razão, suspeita de não poder ser provida, aos olhos das exigências da cognição jurídica, de nenhuma significação. Ela não se constitui, portanto, imediatamente um conceito jurídico, ao contrário.

\section{DELIMITAÇÃO DO PROBLEMA}

Caso se queira, desde logo, progredir, ou seja, tentar propor sobre o tema da responsabilidade política, ou das coisas que se queira assim designar, uma análise que seja realmente jurídica, que veicule outras coisas além das banalidades, dos "quase", ou que é simplesmente mobilizado para expressar opiniões morais, filosóficas ou políticas, que não são em nada verificáveis (e, portanto, não têm seu lugar no processo cognitivo), deve-se desconfiar da falsa familiaridade de termos, tais como responsabilidade política, e se esforçar para cercar o conceito lógico, se ele existe, ao qual este termo remete no domínio jurídico.

Se ele existe, significa aqui simplesmente que não se pode colocar que o termo existe verdadeiramente, quer dizer, que exista um verdadeiro uso do termo. Tudo é aqui assunto de convenção e, tudo se precavendo de qualificar de responsabilidade política somente aquilo que pudesse nos convir (todos os usos não são equivalentes, pelo menos dentro da sua justificação potencial), é necessário admitir que os diferentes significados que o termo recebe (e, eventualmente, outros) podem ser pertinentes.

Mas, para evitar os debates inúteis, que não versam sobre a coisa que a responsabilidade política designaria ou sobre o próprio conceito, mas que estariam relacionadas a um desentendimento dos locutores sobre o sentido que eles dão à responsabilidade política (debate, evidentemente, intransponível: só se pode progredir a respeito do caráter do gato se formos, pelo menos, de acordo com aquilo que entendemos por gato), convém, senão concordar definitivamente sobre o que é a responsabilidade política, pelo menos precisar aquilo que entendemos exatamente pelo termo.

A exigência não é simplesmente teórica. Lê-se sobre os escritos de certos autores que o caso Lewinski conduziu a uma responsabilidade política 
do Presidente Clinton, ao mesmo tempo que outros se insurgiram, qualificando esta responsabilidade como penal: o debate só tem interesse se uns e outros concebem aqui a mesma coisa como responsabilidade política. Ora, é claro que para os primeiros a responsabilidade política é um conceito amplo, incluindo uma forma de responsabilidade penal, desde que ela vise, em um regime político moderno democrático, a pessoa política, e que ela esteja engajada por motivos políticos, enquanto que, para os segundos, a responsabilidade política significa um procedimento específico que só está presente nos regimes que qualificamos como parlamentar, o que não é o caso dos Estados Unidos.

Posto nestes termos, o debate é inútil. Por um lado, duvida-se que haja lugar para o debate, porque as posições não são incompatíveis e que bastaria que cada um definisse sua concepção de responsabilidade política para que isto aparecesse claramente. Por outro lado, se persistimos na questão de saber se um ou outro tem razão em se referir ao conceito de responsabilidade política em sua argumentação, é impossível verificar uma das utilizações e adulterar a outra, pois não existe, a priori, um conceito verdadeiro de responsabilidade política.

\section{USOS DO CONCEITO}

Por esta razão, o primeiro trabalho crítico de uma análise jurídica da responsabilidade política exige que sigamos as diferentes significações que revestem o termo na linguagem do Direito, que mostremos seus pressupostos, que os classifiquemos, etc.

A este respeito, pode-se constatar que a responsabilidade política aparece, na linguagem jurídica, em diversos níveis. Ela pode ser, por um lado, um termo da língua normativa, isto é, um termo que aparece nos atos jurídicos (leis, constituições, decisões da Justiça, etc.) Por outro lado, a responsabilidade jurídica é, claramente, também, um conceito forjado ou utilizado pela doutrina jurídica, seja para descrever o Direito Positivo, seja para formular uma apreciação sobre este mesmo Direito Positivo.

É evidente que o termo não obedece ao mesmo estatuto, segundo o uso que se faz dele - prescrever/descrever - e de acordo com a posição do locutor - político/cognitivo. Compreender a significação jurídica da responsabilidade política determina que se siga também o uso, segundo uma grade de leituras das mais simples e das mais clássicas.

Proponho, então, começar por ver se a coisa pode ter uma significação dentro do próprio direito (o aparelho normativo), em seguida, ver se o conceito serve à Ciência do Direito. Direi algumas palavras, enfim, sobre o vínculo entre os conceitos jurídicos de responsabilidade política e de responsabilidade, que me parece, em última instância, ser a questão essencial do debate sobre a utilização do termo de responsabilidade política. É evidente 
que só poderei, no espaço limitado que me é concedido, dar algumas pistas, evocar algumas hipóteses...

\section{A IMPOSSÍVEL SIGNIFICAÇÃO NO DISCURSO NORMATIVO}

Interesso-me, pois, inicialmente, pelo discurso jurídico propriamente dito, isto é, pelos atos jurídicos e pelas normas que eles veiculam. Meu questionamento é o seguinte: se encontramos nestes atos a expressão de responsabilidade política, o que ela significa exatamente e o que isto implica na construção de um discurso cognitivo de tipo dogmático/doutrinário?

Creio necessário situar e precisar metodologicamente a iniciativa a ser tomada, a fim de evitar todo mal-entendido. De um lado, trata-se de pesquisar se a língua normativa emprega, efetivamente, a expressão, e não de reconstituir teórica e interpretativamente um conceito predeterminado pela análise jurídica (o que será o tema do ponto seguinte do estudo).

A pesquisa é, assim, puramente, uma pesquisa empírica. Por outro lado, se encontramos esta expressão de responsabilidade política nas normas, não poderemos entender sua significação por substituição: é impossível fazer, em comparação com as normas, a pergunta: "o que é a responsabilidade política?" e respondê-la, substituindo à expressão responsabilidade política, uma resposta a priori.

Não se pode partir de um conceito pressuposto de responsabilidade política para conhecer o significado normativo da expressão, mas se deve referir ao conjunto dos enunciados nos quais a expressão responsabilidade política aparece - por exemplo, o enunciado "o governo é politicamente responsável" - indicando então as condições necessárias à verdade de tal enunciado (por exemplo, as condições processuais que permitem exaltar a responsabilidade, a sanção de um tal exortação, etc). ${ }^{2}$

\subsection{Utilização diversificada do termo}

Isto é fácil de entender, pois a norma não obedece a uma exigência de verdade. Sob algumas reservas, que têm uma relação de dependência com um sistema jurídico, ele mesmo, determinado, a autoridade normativa pode chamar o que ela quiser como responsabilidade política. Trata-se, então, de um ato de prescrição que, é claro, não obedece à lógica de um ato de cognição: especialmente, a utilização da língua não responde às mesmas exigências e a expressão responsabilidade política não leva, necessariamente, a uma coisa unívoca e claramente determinada.

De uma maneira geral as expressões da língua normativa podem ser equívocas, vazias de sentido, etc. Pode ser que este efeito seja procurado, explicitamente ou não por motivos políticos, ideológicos. Pode ser, também, que se trate simplesmente de uma conseqüência de uma ausência de rigor 
na utilização do conceito jurídico - ao qual pretendemos nos referir - ou de conhecimento.

\subsection{Variabilidade do conceito}

$\mathrm{Na}$ realidade, para se convencer disso, basta observar que é perfeitamente concebível que dois textos diferentes, em dois sistemas jurídicos diferentes, empregam o termo responsabilidade política em condições processuais incompatíveis ou, no mínimo, amplamente diferentes. Por exemplo, podese muito bem ter uma norma $\mathrm{N}_{1}$ do sistema $\mathrm{S}_{1}$ que utiliza a responsabilidade política em condições de procedimento e de sanção que a assemelhe a uma responsabilidade coletiva do tipo parlamentar, enquanto que a norma $\mathrm{N}_{2}$ do sistema $\mathrm{S}_{2}$ poderá evocar a responsabilidade política, por exemplo, individual do Ministro perante o Chefe do Executivo.

A ocorrência do termo em si não nos ensina nada, pois este termo não designa uma realidade unívoca. E, para dizer a verdade, se a ocorrência intervém, observaremos que a expressão não designa coisa alguma. Conseqüentemente, isolar eventuais empregos normativos do termo responsabilidade política não nos ensina nada mais além do fato de que, em determinado texto, logo em determinado sistema, emprega-se o termo responsabilidade política (este emprego empiricamente constatado) e que neste mesmo texto, sem que se possa tirar vantagem de generalização, o termo é provido de tal significado (que se entende examinando as condições de sua validade). É claro, isto não é nada: sabe-se coisas sobre o sistema jurídico, pode-se proceder a classificações, a apresentações, a comparações. Mas isto não nos ensina nada sobre o conceito de responsabilidade política em si.

\subsection{Substitutividade do termo}

Isto não nos ensina nada porque, imediatamente, vamos comparar as condições de validade do emprego do termo com a grade que, dogmaticamente, construímos ou utilizamos (e que vem de um trabalho que não é um trabalho de constatação empírica sobre a utilização da expressão nas normas).

Diremos, então: em tal texto eis o sentido da responsabilidade política, logo, em tal texto, o termo é utilizado de acordo, ou não, com o que a doutrina ou uma parte dela, entende por responsabilidade política. Mas, nem o uso doutrinário, nem o uso normativo são tais que se possa, aproximando-os, apreciar a verdade do emprego normativo.

E para mostrá-lo ainda com mais evidência, pode-se, simplesmente, tentar substituir o termo responsabilidade política, como normativamente empregado, por um outro termo, qualquer que ele seja, por mais absurdo que possa parecer. 
Veremos que, a despeito do absurdo aparente, a economia normativa não é afetada em nada por essa substituição (simplesmente porque substituir em uma norma não permite definir). Tomemos normas hipotéticas que disporiam assim:

a) quando o governo exalta sua responsabilidade política, o parlamento vota sobre o programa político do governo;

b) quando o parlamento questiona a responsabilidade política do governo, o parlamento vota sobre uma moção de censura;

c) em caso de adoção da moção de censura, de acordo com uma maioria qualificada, ou em caso de rejeição do programa político do governo, este último deve pedir demissão.

Como já foi dito, o que importa nessas normas não é a ocorrência eventual do termo responsabilidade política, mas o fato de que os procedimentos precisos são previstos e que as normas indicam o que se passa quando elas são aplicadas. Por exemplo, se numa iniciativa do governo, o parlamento vota sobre a política geral do governo, que se encontra em minoria, o governo deve pedir demissão, ou que se o parlamento, por iniciativa própria, vota uma moção de censura de encontro à do governo, este deve pedir demissão.

Poder-se-ia assim, substituir, a responsabilidade política por qualquer expressão, por exemplo, Porcelana de Delft, que o significado da norma não mudaria. ${ }^{3}$ Ter-se-ia, assim, três normas hipotéticas, assim enunciadas:

a) quando o governo exalta sua Porcelana de Delft, o parlamento vota sobre o programa político do governo;

b) quando o parlamento questiona a Porcelana de Delft do governo, o parlamento vota sobre uma moção de censura;

c) em caso de adoção da moção de censura, de acordo com uma maioria qualificada, ou em caso de rejeição do programa político do governo, este último deve pedir demissão...

Nós o vemos assim: pouco importa o que se põe como termo normativo mediano, este termo não preenche uma função lógica, mesmo se, é claro, ele tenha uma forte conotação ideológica, e pode muito bem aparecer, por outro lado, corretamente empregado a respeito de uma teoria doutrinária da responsabilidade política.

\subsection{A utilização dúbia da expressão na Constituição francesa}

Não analisei todos os textos de direito positivo, nem todos os textos antigos, mas me parece, por exemplo, muito significativo que os artigos 49 e 50 da Constituição de 1958 não utilizem este termo preferindo o de "responsabilidade do governo", que fala sobre um programa ou sobre uma declaração de política geral. 
É claro que se uma parte da doutrina vai, a partir disto, construir o conceito de responsabilidade política, o próprio texto fala simplesmente (aparentemente de forma mais precisa, designando o órgão) de responsabilidade do governo. É claro, também, que o termo político não tem a mesma significação quando doutrinariamente ele é associado à responsabilidade para qualificá-la e constituir, também com ela, um conceito e quando, normativamente, ele designa como aqui uma das modalidades a partir da qual o governo pode engajar sua responsabilidade.

Em compensação, a Constituição se serve expressamente dos termos de responsabilidade penal para designar um certo tipo de ação contra, por exemplo, o Presidente da República ou os Ministros (Título X). Sem ser determinante, essa comparação mostra usos extremamente diferenciados dessas expressões, enquanto elas nos parecem, conceitualmente, próximas e intuitivamente familiares.

\subsection{Outros problemas sobre o significado da expressão}

Concluindo, pode-se dizer que o discurso normativo não nos ensina nada sobre a responsabilidade política como tal, porque não seria esta a função da norma: o que deixa livre, de um certo modo, a doutrina se referir a este termo para designar alguma coisa, com a condição de precisar, assim, o que ela designa. Sem desenvolver um pouco mais, vemos um outro problema de significação que está ligado ao uso doutrinal.

\section{CONDIÇÕES DA CONSTRUÇÃO DE UM CONCEITO DOUTRI- NÁRIO}

A partir de agora, minha interrogação vai ser totalmente diferente: tratar-se-á simplesmente de saber se existe, e em quais condições de verdade lógica, um conceito de responsabilidade política, a partir do qual a doutrina presta contas do direito. De outra maneira, é preciso se perguntar se a responsabilidade política da qual os juristas falam subsume um certo número de feitos jurídicos empíricos, diversos porque depende de vários sistemas jurídicos, qualificados ou não, por esses sistemas de responsabilidade política, ou de qualquer outro nome, e como ela o faz.

Aqui ainda, devo começar por um certo número de pontos precisos. Inicialmente, é preciso lembrar que a doutrina não está obrigada a se referir a este conceito, e nós vimos que a ausência de significação normativa, per se, da expressão dá à doutrina a total responsabilidade do uso construtivo que ela faz.

Em seguida, convém dizer que a definição jurídica (que depende, então, da Ciência do Direito) da responsabilidade política é, necessariamente, estipulativa: ela surge com a construção do objeto pela Ciência do Direito. 
A questão pertinente é, pois, saber: a qual construção corresponde essa utilização? Deve-se recorrer a ela com relação ao que se procura? Em relação ao que é, ou a que deve ser, a Ciência do Direito?

Conseqüentemente, é possível que, de acordo com os autores, o recurso ao conceito difira e dependa de diversos elementos para se revestir de múltiplas significações. Não tenho o propósito de preparar um catálogo do uso doutrinário. Gostaria, simplesmente, de mostrar tendências, para fazer perceber os riscos contidos na utilização do conceito. Resumindo, pode-se, então, distinguir em dois tempos: o contexto da utilização (prescritivo, descritivo) e qual é o significado dado por essa utilização (amplamente ou de maneira restritiva).

\section{O MODO DE PENSAR PRESCRITIVO}

Freqüentemente, constata-se que a doutrina adota uma atitude prescritiva. Ela parte de uma idéia a priori, seja do que é, em geral, a responsabilidade (em matéria política ou, mais amplamente, em todas as matérias jurídicas), seja do que devem ser as pressões que pesam sobre os governantes, por exemplo, em uma democracia, seja dos dois. A partir dessa concepção $a$ priori, ela constrói um conceito de responsabilidade política.

É uma atitude ética, política, que visa fornecer um padrão de retidão a respeito do qual será apreciado o direito positivo (ao mesmo tempo em seu texto e em seu funcionamento). Esta atitude é, ao que me parece, aquela que adota Olivier Beaud em sua obra sobre o sangue contaminado ${ }^{4}$, ou ainda Philippe Ségur ${ }^{5}$ ou Christian Bidégaray e Claude Emeri ${ }^{6}$.

É claro que essa atitude leva a uma conceitualização e isto serve na Ciência do Direito. Essa abordagem autoriza uma definição de critérios objetivos da responsabilidade política, mesmo se, naturalmente, persistam debates sobre a identificação destes critérios em função do padrão adotado: critérios processuais (exaltação e sanção da responsabilidade política); critérios orgânicos (órgão sobre o qual pesa a responsabilidade política, reenviado, na maioria das vezes, ao governo).

\subsection{Ineficácia atual da expressão}

Mas, ao mesmo tempo, a vontade prescritiva pode deslocar o propósito longe das exigências da Ciência do Direito, e levar a uma simples apreciação política dos efeitos políticos do Direito.

Tal é o caso, me parece, quando se evoca abundantemente e contra a vontade o desuso da responsabilidade política: isto supõe de um lado que se tenha um modelo a priori do qual se constataria o desuso (geralmente os procedimentos do parlamentarismo clássico ${ }^{7}$ ); isto supõe ainda que o desaparecimento ou o recuo deste modelo a priori seja objeto de uma avaliação 
política. $\mathrm{O}$ mesmo acontece quando, muitas vezes, destaca-se a ineficácia atual da responsabilidade política. Enfim, e sobretudo, este deslize inerente à atitude prescritiva é muito significativo quando, apresentando a responsabilidade política, damos a ele uma finalidade: geralmente assegurar o equilíbrio dos poderes.

\subsection{Pressupostos e consequências}

O que me parece, então, inspirar tais considerações é a idéia implícita de que existiria um modelo, senão perfeito, pelo menos melhor, de organização jurídica do poder: este modelo seria o regime parlamentar. É ele que estaria, inicialmente, comprometido com a responsabilidade política (encontra-se a idéia de equilíbrio entre poderes, de função da responsabilidade política na relação entre o parlamento e o governo); é para ele que deveríamos voltar (esta idéia está no centro do debate sobre a responsabilidade política e a responsabilidade penal dos governantes: Cf. Olivier Beaud); e é na medida deste regime que se julga os outros regimes (sobretudo o regime presidencialista). Evidentemente, em razão da relativa especificidade do regime da $5^{\text {a }}$ República, a iniciativa toma uma importância singular para a doutrina francesa atual.

A definição estipulativa da responsabilidade política tende, pois, a fornecer um critério de demarcação entre o regime parlamentar, que ela caracterizaria, evidentemente, e os outros regimes políticos que conheceriam, eventualmente, outras formas de responsabilidade dos governantes.

Ora, uma tal demarcação supõe duas coisas: de um lado, a unidade dos regimes parlamentares; de outro lado, a assimilação da responsabilidade política no jogo clássico da moção de censura e da questão de confiança. Deste ponto de vista, o primeiro tópico está para ser demonstrado (e o exemplo francês mostra pelo menos, que há diferenças entre regimes parlamentares). Quanto ao segundo, ele é fruto da definição e torna-se tautológico: se não há nenhuma dificuldade em conceituar a responsabilidade política como a subsunção dos procedimentos parlamentares clássicos (v. o ponto seguinte), não se pode tirar desta iniciativa estipulativa o caráter de uma verdade que impediria de ver além, uma responsabilidade política, por exemplo, no engajamento por motivo político da responsabilidade penal do Presidente dos Estados Unidos.

\section{A PERSPECTIVA DA EXPRESSÃO SOB O PONTO DE VISTA DES- CRITIVO}

Quando, ao contrário, se depara com uma iniciativa de tipo exclusivamente descritivo, como aquela da qual reclama o positivismo, as coisas são um pouco mais complexas. Diferentemente da iniciativa prescritiva, não partiremos de uma conceitualização a priori, mas faremos antes por um movi- 
mento indutivo, para avaliar se é possível subsumir sob o termo de responsabilidade política um certo número de procedimentos previstos pelo direito positivo e que envolvem os governantes. Aqui, as respostas são variáveis.

\subsection{A recusa da idéia de responsabilidade jurídica}

Para alguns autores, por exemplo, a equipe reunida por Louis Favoreu, não há necessidade de mobilizar o conceito, já que ele não tem utilidade na descrição do Direito Positivo: a responsabilidade política é ignorada enquanto conceito (a utilização moderada do termo remetendo ao uso da língua familiar) sem que isto afete em quer que seja o relatório dos procedimentos de controle sobre os governantes. ${ }^{8}$

Com efeito, de um lado, a abordagem é, então, mais orgânica que processual (descreve-se órgãos, seu estatuto, sua função); de outro lado, evita-se, voluntariamente, recorrer a qualquer conceito de responsabilidade política, pois recusa-se ver na minoria do governo e na obrigação de pedir demissão que se segue, uma sanção jurídica: não é, como se diz, a conseqüência da violação de uma regra. ${ }^{9}$

É, pois, a partir de uma teoria geral da responsabilidade (civil e outras) que uma parte da doutrina rejeita, mais ou menos definitivamente, o conceito de responsabilidade política.

\subsection{A admissão do conceito: a responsabilidade política é uma categoria de responsabilidade jurídica}

Outros autores vão menos longe no questionamento do conceito a priori de responsabilidade política: assim Georges Burdeau, Francis Hamon e Michel Troper reservam um lugar ao conceito. Mas a responsabilidade política é então tratada como um dos três casos de responsabilidade que pesam sobre os governantes (responsabilidade ministerial) ao lado da responsabilidade civil e penal ${ }^{10}$ (enquanto para a equipe de Louis Favoreu a responsabilidade dos governantes se opõe à responsabilidade civil e penal, tratada por outro lado). ${ }^{11}$

É interessante observar que é também, a partir de uma teoria geral da responsabilidade que estes autores vêem no procedimento de engajamento o critério da responsabilidade política que permite distingui-la da responsabilidade civil ou penal. Isto supõe que estas três formas de responsabilidade podem ter a mesma finalidade (política) e versar sobre os mesmos atos.

A responsabilidade política é, pois, aqui no sentido jurídico, uma categoria da responsabilidade política no sentido político, que se define processualmente e que remete a um regime de tipo parlamentar. Os autores não escondem a ambigüidade da existência de dois procedimentos diferentes (até mais): a moção de censura (na qual o parlamento questiona a responsa- 
bilidade política do governo); as questões de confiança (que permitem ao governo engajar sua própria responsabilidade política).

\section{9 É POSSÍVEL UMA DEFINIÇÃO CIENTÍFICA COMPLETA?}

Concluindo este ponto, pode-se constatar que a responsabilidade política dos juristas depende mais de uma teoria política, que de uma teoria jurídica. Ela serve para descrever o Direito, mas ela não é necessariamente teorizada já que o enunciado de critérios parece ser o aporte principal (critérios de identificação e de demarcação). Ela serve para julgar o Direito, em um processo de cognição mais ética que jurídica.

Uma interrogação permanece em suspense para a Ciência do Direito, se queremos teorizar a responsabilidade política, isto é, fazer dela um conceito jurídico. Pode-se pensar em fornecer uma definição estipulativa científica que não deixa de lado os regimes não parlamentares e a criminalização da vida política? Logo, ter uma teoria ampla da responsabilidade jurídica intervindo em matéria política?

\section{0 É ELA UM CONCEITO SUI GENERIS?}

Minha pergunta aqui é simples e se refere à própria construção de conceito. Enquanto a origem histórica inglesa se posiciona do lado do trustee, da confiança, a conceitualização da responsabilidade política não pode fazer economia, parece-me, de uma clarificação sobre seu vínculo com a própria idéia de responsabilidade

Assim, deve-se tentar ver o que é (ou pode ser) a este respeito a responsabilidade política dos juristas: é um conceito sui generis, sem relação com o conceito de responsabilidade geral (é de uma certa maneira a tese adotada pela equipe reunida por Louis Favoreu, mas também, em uma outra perspectiva, por Olivier Beaud?) ou é uma forma específica da responsabilidade jurídica (e vimos que é ao que levava a análise de Georges Burdeau, Francis Hamon et Michel Troper).

\section{COMO CONSTRUIR ESTE CONCEITO?}

De outra maneira, convém agora se perguntar a que remete a responsabilidade política quando um jurista diz que um ministro é ou não é, ou não é mais, politicamente responsável? O que ela significa? Como é ela construída?

Parece-me que a verdadeira questão jurídica está ai. Quero dizer que todos os nossos debates atuais sobre a criminalização da responsabilidade política, seu desuso, etc, dependem, em grande parte, da resposta que damos a essa pergunta. E que debater sobre isto, se nós não esclarecemos previamente este ponto, é um pouco inútil. 
Lembremo-nos, por exemplo, que quando Raymond Carré de Malberg escrevia que a responsabilidade penal dos ministros era a busca da responsabilidade política, ele queria simplesmente dizer que no âmbito processual que faz intervir um juiz especial e subtrai o política no Direito comum, as noções em causa são providas de uma significação totalmente diferente daquela que se atribui à responsabilidade ordinária ou geral.

É, pois, em função da resposta que nós damos à esta questão das relações entre responsabilidade política e responsabilidade geral, como conceitos doutrinariamente construídos, isto é, em função da maneira pela qual nós estipulamos o conceito de responsabilidade política, que vamos reter tal ou tal apresentação do direito positivo. Não que toda apresentação seja necessariamente correta (outros elementos, que não vou lembrar aqui, intervêm) mas que diversas posturas são suportáveis com a condição de serem assumidas (isto é, com a condição de assumir suas implicações e a lógica).

\subsection{A problemática sancionatória}

O que está aqui em jogo é o lugar, não simplesmente do procedimento (o que é apreendido como o elemento chave na procura de um critério da responsabilidade política), mas, imediatamente, a questão da sanção e do eventual ato ilícito. É claro que esta questão que remete, em aparência, muito intensamente à idéia de um julgamento moral sobre uma ação política, e à idéia, também moral, de que aquele a quem foi confiado um poder, ou uma função, deveria prestar contas, foi fortemente, em um primeiro momento, limitada pela análise científica. Mas ela não pode ser totalmente expulsa da problemática e ao contrário, contribui para esclarecer com a condição de ser colocada em termos jurídicos.

\subsection{Ausência de ilícito jurídico propriamente dito}

A idéia geral que prevalece, de agora em diante, na doutrina jurídica é que no caso da responsabilidade política, não há falta no sentido jurídico. $\mathrm{E}$, conseqüentemente, não é possível caracterizar juridicamente o conceito de responsabilidade política pela dupla ato ilícito-sanção, como seria o caso em matéria de responsabilidade geral. $\mathrm{O}$ conceito de responsabilidade política, conceito sui generis, seria assim totalmente cortado da lógica da responsabilidade jurídica.

Não há ato ilícito em matéria de responsabilidade política, de acordo com esta análise, porque o ato ilícito, no sentido político, pressuporia a própria violação de uma regra jurídica. Ora, a sanção que é dada pelo voto do parlamento, por exemplo, que obriga juridicamente o governo a se demitir, não é senão a constatação jurídica de que uma regra não foi respeitada, mas a afirmação de que o governo não encarna mais as opções políticas que o parlamento pretende fazer respeitar. 
A sanção dada, politicamente, por autoridades políticas e por motivos políticos, será pois uma sanção puramente política. Por esta razão, ela conhece um regime jurídico especial (os procedimentos específicos, particularmente os procedimentos que caracterizam o regime parlamentar). Esta tese, doravante clássica, constrói a responsabilidade política como um conceito específico totalmente distinto das responsabilidades civil, penal ou administrativa, por exemplo.

Está na lógica dessa construção criticar a criminalização da justiça política, isto é, a intervenção do procedimento ordinário (mais ou menos ordinário) e dos juizes do direito comum (mais ou menos comum) no processo da sanção política.

Esta tese, esta construção específica leva a várias conseqüências lógicas, que nem sempre são admitidas ou dominadas pelos adeptos dessa construção e que são, então, fontes de inúmeras ambigüidades na utilização e significação do conceito. Citarei duas que defendem que a aparente vontade de proceder à construção do conceito independentemente da idéia de ato ilícito não está totalmente declinada, e traz paradoxalmente uma negação de ato jurídico ilícito para melhor reintroduzir, por um curioso retorno, uma concepção mais moralizante do ato ilícito, que a análise jurídica pretendia combater.

Uma primeira conseqüência, bastante extremista e muito pouco mobilizada $^{12}$, é que o conceito se encontra tão mineralizado com relação à lógica da própria responsabilidade, que se pode perguntar se ainda é oportuno, de um ponto de vista dogmático, recorrer a ele.

Por que então manter a utilização do termo de responsabilidade política se a própria definição do conceito se faz sobre o axioma de que esta responsabilidade política nada tem a ver com a responsabilidade? Não é senão, por equívoco, ou por razões ideológicas (visando reclamar esta responsabilidade política ou, mais exatamente, manter a idéia de ato ilícito, de uma sanção que se sabe ser jurídica e fazê-la assim beneficiar-se da bagagem legitimamente ligada à idéia da própria responsabilidade).

E, já dissemos, pode-se muito bem descrever os procedimentos jurídicos que se pretende subsumir sob o conceito específico de responsabilidade política sem dever referir-se a este conceito, estipulativo. Referir-se a ele nunca é neutro e não pode jamais pretender-se como tal, particularmente quando se faz suas essas premissas...

Uma segunda conseqüência está ligada à caracterização assim operada da responsabilidade política por um sistema processual, o regime parlamentar. Dizer que são os procedimentos específicos do regime parlamentar que fazem com que haja responsabilidade política supõe que o desaparecimento ou a mutação do regime político considerado possa causar, sem que haja cientificamente nada a dizer, o desaparecimento da responsabilidade 
política. A este respeito, há ainda alguma ambigüidade à defender, a todo preço, para a manutenção do conceito fora deste sistema original. $\mathrm{O}$ que parece, então, ser um jogo na utilização deste conceito sui generis não é tanto a responsabilidade do político, mas a vontade de solidificar esta em um procedimento predeterminado e, logo, de limitar a liberdade política da organização jurídica.

\subsection{A reintrodução, no âmbito jurídico, do ato ilícito e da sanção política}

Ao contrário desta tese clássica, é também possível afirmar que a responsabilidade política é um tipo de responsabilidade. É preciso, caso se adote esta posição, - que não é nem menos, nem mais pertinente, mas simplesmente diferente - possível reintroduzir juridicamente a noção de ato ilícito e de sanção.

O que é então a acepção de ato ilícito e da suposta violação da regra do direito? Prima facie, pode-se dizer que na época em que existe para a administração, até mesmo para o particular, uma responsabilidade de tipo objetivo, não há nada de original e extraordinário em conceber a idéia de uma sanção jurídica independentemente de ato ilícito. Se o argumento classicamente evocado fosse somente este, creio que não haveria nenhuma dificuldade. Ora, na realidade, diz-se que a sanção jurídica, mesmo independentemente de um ato ilícito, reside sempre na violação de uma regra de direito. A afirmação mereceria uma longa análise.

Mas, com efeito, pode-se dizer que quando o juiz sanciona juridicamente um comportamento, quer tenha havido ato ilícito ou não, é porque este comportamento seria diretamente contrário a uma diretriz do direito ${ }^{13}$ ou porque o juiz se julga investido do poder de apreciar diretamente um comportamento.

O primeiro caso é aquele, por exemplo, da violação de uma regra penal, que o juiz sanciona. O segundo é aquele em que o juiz, por exemplo, vai considerar que tal comportamento do pai é contrário ao interesse do filho. Nos dois casos, a posteriori, considerar-se-á que há a sanção jurídica de um ato ilícito que é, seja de não ter respeitado a diretriz, seja de não ter apreciado corretamente o interesse do filho.

A afirmação de que só haveria sanção no caso da violação da regra de direito é uma maneira, sem dúvida um pouco rápida, de remeter a estas duas situações; se não fosse o caso, ela não corresponderia à realidade do direito positivo.

É preciso então se perguntar se a situação difere em matéria de responsabilidade política. Não acredito.

Pode-se, assim, dizer - e reintroduzir-se-á, caso se deseje, a idéia, ainda que ela não seja necessária - reencontrando a própria definição do político, que em um regime parlamentar (por exemplo), os governantes têm 
por obrigação continuar a receber a confiança da assembléia. É um contrato (prefiro o termo inglês trustee, difícil de devolver, mas que mostra que a assembléia investe o governo de sua confiança, mas é suscetível retirá-la a qualquer momento sem ter que se justificar, como em uma relação de depósito bancário ${ }^{14}$ ) entre governantes e assembléias.

O governo deve conservar esta confiança que é o fundamento jurídico de seu poder. Aquele que perde esta confiança comete uma falta no sentido jurídico e sua sanção jurídica reside na perda do poder. Não encontrando erro, poder-se-á muito bem dizer que a assembléia está habilitada, juridicamente (pela Constituição), para apreciar soberanamente se o governo governa segundo suas idéias. Encontramos dois eixos da sanção jurídica acima citadas: o desrespeito de uma diretriz (Código Penal, ou trust), a sanção por diferença de apreciação pela autoridade jurídica (o juiz, a assembléia).

O essencial, pois, é pôr em evidência o que não causa dificuldade particular, que este mecanismo de responsabilidade está previsto pelo direito. A este respeito, não é juridicamente original que se substitua ou se acrescente, eventualmente, a esta forma processual uma outra forma no âmbito de uma outra prescrição normativa.

E deste ponto de vista, partindo dessa concepção do poder político, pode-se generalizar a responsabilidade política a qualquer tipo de responsabilidade do político, já que é uma forma de responsabilidade cuja originalidade vem do contexto político que ela apreende, logo à finalidade política. Dependem logicamente da responsabilidade política definida estipulativamente desta maneira, a moção de censura como a questão de confiança, as comissões parlamentares, como a responsabilidade penal, em regime presidencial ou em regime parlamentarista ou, ainda, em outros regimes.

Do mesmo modo, não há nenhum motivo para não considerar como forma de responsabilidade política, assim determinada, a dissolução da câmara ou a reeleição (ou a ausência de reeleição) do pessoal político. A cada vez se observará uma sanção vinda de um órgão político (incluído o corpo eleitoral) para um outro órgão político por motivos políticos. E a cada vez se encontrarão os eixos da sanção jurídica.

Não há então nenhum motivo se partimos destas premissas para se reservar o conceito de responsabilidade política ao regime parlamentar. A responsabilidade política é, nesta lógica, a responsabilidade do político, qualquer que seja e quaisquer que sejam suas formas. Ela unifica procedimentos jurídicos muito diversos, enviados a segundo plano em uma análise global do político.

\section{SÍNTESE CONCLUSIVA}

O conceito de responsabilidade política é, desta maneira, um conceito puramente doutrinário. Ele não é provido de nenhuma significação verdadei- 
ra, e é estipulativamente construído. Para que debates jurídicos sobre este conceito possam ser evitados ou regulados, deve-se se ater simples e rigorosamente a uma análise lógica das teorias que constroem o conceito. Tomado como um conceito específico, ele designa, essencialmente, os procedimentos do regime parlamentar, mas não há, então, nenhuma razão de devolver à idéia de responsabilidade e sua utilização põe, necessariamente, em movimento considerações metajurídicas. Tomado como declinação da responsabilidade, ele designa logicamente toda forma de responsabilidade do político, independentemente das técnicas que a realizam juridicamente e se pode perguntar se ele designa ainda, realmente, qualquer coisa de juridicamente preciso.

\section{REFERÊNCIAS BIBLIOGRÁFICAS}

BEAUD, O. Le sang contamine. Paris: PUF, 1999.

BIDEGARAY, Christian \& EMERI, Claude. La responsabilité politique. Paris: Dalloz, 1998.

BURDEAU, G.; HAMON, F. \& TROPER, M. Droit Constitutionnel. Paris: Dalloz, 1997.

COHENDET, Marie-Anne. La cohabitation. Paris: PUF, 1993.

FAVOREU, L.; Gaïa, P. ; GHEVONTIAN, R.; et alli. Droit constitutionnel. Paris: Dalloz, 1998.

GARCIA, Eloy. Estudia Preliminar à la Lógica Parlamentaria, o de las reglas del buen parlamentario. In: HAMILTON, W. G. Parliamentary Logick. Textos Parlementarios Clàssicos. Madrid, 1996.

HART, H. L. A. Definition and Theory in Jurisprudence. Oxford, 1953.

ROSS, A. Definition in Legal language. Logique et Analyse, Bruxelles, août 1958, p. 139 e ss. (trad. francesa, in: Matzner, E. Droit et langues étrangères: concepts, problèmes d'application, perspectives. Presses Universitaires de Perpignan, 2000).

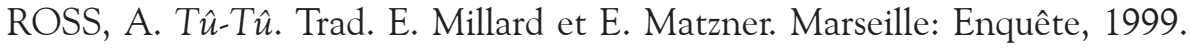

ROSS, Alf. Directives and Norms. Londres: Routlegde, 1968.

SEGUR. La responsabilité politique. Que-sais-je? n. 3294. Paris: PUF, 1998.

\footnotetext{
${ }^{1}$ BIDEGARAY, Christian \& EMERI, Claude. La responsabilité politique. Paris: Dalloz, 1998.

2 Comp. HART, H. L. A. Definition and Theory in Jurisprudence. Oxford, 1953. Cf., ainda: ROSS, A. Definition in Legal language., Logique et Analyse, Bruxelles, août 1958, p. 139 e ss. (tradução francesa, in: Matzner, E. Droit et langues étrangères: concepts, problèmes d'application, perspectives. Presses Universitaires de Perpignan, 2000).

${ }^{3}$ Sobre esta análise, cf. ROSS, A. Tû-Tû. Trad. E. Millard et E. Matzner. Marseille: Enquête, 1999, p. 263 e ss.

${ }^{4}$ Beaud, O. Le sang contamine. Paris: PUF, 1999.
} 
${ }^{5} \mathrm{Ph}$. Ségur. La responsabilité politique. Que-sais-je? n 3294. Paris: PUF, 1998.

${ }^{6}$ Loc. cit.

${ }^{7} \mathrm{Ou}$, pelo menos, o recurso explícito a esses procedimentos. E não é meu propósito aqui, mas notemos, de qualquer forma, que há ingenuidade, para não dizer mais, em ver o desuso dos procedimentos parlamentares de responsabilidade política (assim definidos) sob o pretexto de que não há maioria política na Assembléia, que os motivos de censura são raramente adotados, e que a questão de confiança é votada geralmente. De uma parte, é ignorar totalmente a idéia de ameaça e de economia no sistema: como explicar juridicamente e politicamente as tolerâncias ideológicas, por exemplo, senão pela responsabilidade política efetiva do governo, e o excelente conhecimento da mecânica de certa responsabilidade pelos atores políticos? Falar, então, de desuso e incompreensão: é bem o inverso do que ele trata. Cf. sobre esse ponto as análises importantes de Marie-Anne Cohendet, notadamente: La cohabitation. Paris: PUF, 1993. Como, de outra parte, se prender a um discurso - não jurídico, efetivamente - que tende a valorisar o parlamentarismo através da responsabilidade política, e julgar que ele há desuso desta responsabilidade política não se traduz pela queda dos governos? É o parlamentarismo que nós conhecemos politicamente valorisado ou a instabilidade parlamentar? Há às vezes, atrás dos lugares comuns, lógicas implacáveis...

${ }^{8}$ FAVOREU, L.; Gaïa, P. ; GHEVONTIAN, R.; e outros. Droit constitutionnel. Paris: Dalloz, 1998. « La responsabilité politique est évoquée de manière générale en 5 lignes ( ${ }^{\circ}$ 944); puis annoncée pour décrire le parlement sous la Vème République, elle devient responsabilité du gouvernement, reprenant les termes de la constitution de 1958. Il n'y a pas de théorie générale de la responsabilité politique ».

${ }^{9}$ Id. Ibidem, n. 988.

${ }^{10}$ BURDEAU, G.; HAMON, F. \& TROPER, M. Droit Constitutionnel. Paris : Dalloz, 1997, p. 355. Cf., ainda, p. 115-116.

${ }^{11}$ FAVOREU, op. cit., n. 944 e 946.

${ }^{12}$ V., no entanto, L. Favoreu et alii, op. cit.

${ }^{13}$ Sobre as diretivas do Direito : V. ROSS, Alf. Directives and Norms. Londres: Routlegde, 1968, p. 34 e ss.

${ }^{14}$ Sobre esta origem do trust, V. notadamente os trabalhos esclarecedores de Eloy Garcia, e, particularmente: Estudia Preliminar à la Logica Parlamentaria, o de las reglas del buen parlamentario. In: HAMILTON, W. G. Parliamentary Logick. Textos Parlementarios Clàsicos. Madrid, 1996.

\author{
ABSTRACT \\ The article deals with the difficulties involving the \\ meaning of the idea of political responsibility.
}

KEYWORDS

Critical analysis. Meaning. Political Responsibility. 